\title{
Prevalence of Tuberculosis in Children After Natural Disasters, Bohol, Philippines
}

\author{
Kristy O. Murray, Nina T. Castillo-Carandang, Anna M. Mandalakas, Andrea T. Cruz, Lauren M. Leining, \\ Salvacion R. Gatchalian, on behalf of the PEER Health Bohol Pediatric Study Team ${ }^{1}$
}

In 2013, a severe earthquake and typhoon affected Bohol, Philippines. To assess the postdisaster risk for emergence of Mycobacterium tuberculosis infection in children, we conducted a cross-sectional multistage cluster study to estimate the prevalence of tuberculin skin test (TST) positivity and tuberculosis (TB) in children from 200 villages in heavily affected and less affected disaster areas. Of the 5,476 children we enrolled, 355 were TST-positive (weighted prevalence $6.4 \%$ ); 16 children had active TB. Fourteen ( $7 \%$ ) villages had $\geq 20 \%$ TST-positive prevalence. Although prevalence did not differ significantly between heavily affected and less affected areas, living in a shelter with $\geq 25$ persons approached significance. TST positivity was independently associated with older age, prior TB treatment, known contact with a person with TB, and living on a geographically isolated island. We found a high TST-positive prevalence, suggesting that national programs should consider the differential vulnerability of children and the role of geographically isolated communities in TB emergence.

$I^{\prime}$ n October 2013, the island province of Bohol, Philippines, was devastated by a 7.2-magnitude earthquake, followed 3 weeks later by the landfall of Typhoon Haiyan (Super Typhoon Yolanda). These disasters resulted in the deaths of 195 persons in the province; displacement of $30 \%$ of the 1.2 million-person population (1); and disruption of routine health services, including prevention and treatment services provided by the National Tuberculosis Program (2). After other natural disasters, infrastructure loss resulted in individual patients being contagious for longer periods, and increased Mycobacterium tuberculosis transmission occurred because of crowding in emergency shelters (3). In complex emergencies, children are the most vulnerable population and suffer the greatest negative effects (4).

Author affiliations: Baylor College of Medicine and Texas Children's Hospital, Houston, Texas, USA (K.O. Murray, A.M. Mandalakas,

A.T. Cruz, L.M. Leining); University of the Philippines, Manila,

Philippines (N.T. Castillo-Carandang, S.R. Gatchalian)

DOI: https://doi.org/10.3201/eid2509.190619
Approximately 400,000 children live in Bohol, so the increased risk for tuberculosis (TB) emergence after these natural disasters was expected to be substantial. To further complicate matters, the main island province of Bohol includes 75 smaller islands and islets that are considered geographically isolated and disadvantaged areas $(5,0)$. These areas are separated from mainstream society and have both physical (i.e., accessible only by boat) and socioeconomic factors that further compound their vulnerability to TB.

In this study, our primary objectives were to estimate the prevalence of $M$. tuberculosis infection and TB disease between displaced and nondisplaced children and examine risk factors for $M$. tuberculosis infection. We aimed to clarify the epidemiology of childhood TB in the late postdisaster recovery setting and provide recommendations to mitigate damage and ensure preparedness before future complex emergencies.

\section{Methods}

\section{Study Population}

We conducted this study in the island province of Bohol in the Philippines during 2016-2018. Bohol is 4,821 km and comprises 1 city, 47 municipalities, and 1,109 villages (called barangays). In 2010, the total population of Bohol was $\approx 1,255,128$, of whom $32 \%$ were children (7). The World Health Organization estimates that $>80 \%$ of children are vaccinated with $M$. bovis BCG at birth in the Philippines (8).

\section{Study Design}

To estimate the prevalence of tuberculin skin test (TST) positivity and TB in children $(<15$ years of age), we conducted a cross-sectional survey using a modified version of a multistage cluster sampling technique based on the World Health Organization's Expanded Programme on Immunization coverage survey methods (9). Based on our initial

\footnotetext{
${ }^{1}$ Additional members of the PEER Health Bohol Pediatric Study Team who contributed data are listed at the end of this article.
} 
sample size calculations, we determined that we needed to screen a minimum of 4,014 children ( $0-14$ years of age) to identify a significant difference between our hypothesized postdisaster prevalence of $M$. tuberculosis infection (1\%) and a reference value of $0.56 \%$ prevalence of infection $(\alpha=0.05$, power $=80 \%)(10)$. To account for the possibility of missing data or incomplete or inaccurate records, we aimed to sample 4,200 children.

Using 7 households per cluster and an estimated minimum average of 3 children per household, we determined we needed 200 clusters to obtain our sample size. The 200 clusters comprised 100 clusters chosen from the municipalities that suffered the greatest effects of the natural disasters (heavily affected areas) and 100 clusters from municipalities that suffered fewer effects (less affected areas) based on data from the Provincial Health Office (Reymoses Cabagnot, Provincial Health Officer, pers. comm., 2015 Aug 17). We randomly selected 7 municipalities each from heavily affected and less affected areas, providing 14 municipalities total for sampling.

To select the 200 clusters, we alphabetically arranged the names of all villages and their population sizes (based on the 2010 census), stratified by heavily affected area and less affected area designation. We determined the sampling interval by dividing the total population of each area (224,212 in heavily affected areas and 214,072 in less affected areas) by the number of clusters needed. We identified the first cluster (village) by using a randomly generated 5-digit number and matching it to the first village in our list with a cumulative population greater than or equal to the random number. We identified the second cluster by adding the sampling interval to the random number and selected subsequent clusters by adding the sampling interval to the previously generated number until we identified 100 clusters in each area (Appendix Tables 1, 2, https://wwwnc. cdc.gov/EID/article/25/10/19-0619-App1.pdf).

Once we identified all 100 clusters in each area, we selected the households for enrollment using simple random sampling in the field. We worked with the barangay health stations to obtain a list of all the households within the village, which we then randomly selected using a random number generator. The household number randomly drawn was the starting point of the survey. Each subsequent household was chosen by going to the next closest front door. If no one was home, then the next house was selected, until a total of 7 households containing $\geq 1$ child were obtained for each of the 200 clusters (total households 1,400). All children within the household were enrolled.

All 1,400 households had an equal chance of being selected to participate in this survey. Children were excluded if caregivers did not provide consent or if child assent for those $\geq 7$ years of age was not obtained. We conducted surveys using 2 questionnaires, 1 for the household in general and 1 for each child assessed. Surveys assessed social risk factors for M. tuberculosis infection, including whether or not the child was residing in Bohol during the disasters, displacement into an emergency shelter or camp, and number of new permanent or temporary residents in households who were displaced as a result of the disasters. We also assessed history of TB treatment and determined whether the children received their healthcare from the public or private sector. Caregivers completed screening for pulmonary TB using the National Tuberculosis Program questionnaire that assesses cough, weight loss, fever, and TB exposure (11); an examination for cervical lymphadenopathy $(\geq 2 \times 2 \mathrm{~cm})$; and TST ( 5 tuberculin units purified protein derivative-S, Serum Statens Institute, https://en.ssi.dk) (Figure 1).

\section{Clinical Evaluation for TB}

The study team returned to each enrolled household 4872 hours after the initial visit to measure the TST induration transversely in accordance with National Tuberculosis Control Program guidelines (11). All children who had TSTs $\geq 10 \mathrm{~mm}$ (or $\geq 5 \mathrm{~mm}$ if recent TB exposure within the last 6 months was known), had TB-compatible signs or symptoms, or both completed further evaluation for TB. Evaluation included physical examination, chest radiography, and microbiologic testing of sputum (children $>5$ years of age) or gastric aspirates (children $\leq 5$ years of age) by direct smear sputum microscopy and GeneXpert PCR testing (Cepheid, http://www.cepheid.com); mycobacterial culture was not available. All TST-positive or symptomatic children were provided with transportation to the closest medical center along with a voucher for chest radiograph. An independent radiologist read the chest radiographs to determine the presence of lesions consistent with intrathoracic TB.

Participants in whom M. tuberculosis infection or TB disease was diagnosed were referred to the local health center for appropriate treatment. M. tuberculosis infection was defined as TST results $\geq 10 \mathrm{~mm}$ in asymptomatic children with normal chest radiograph results and negative direct smear sputum microscopy and PCR. In accordance with international and national guidelines $(11,12)$, TB was diagnosed in children who met 3 of the 5 following criteria: 1) TST positive, 2) known exposure to a TB contact, 3) evidence of TB on chest radiograph, 4) direct smear sputum microscopy or PCR positive in sputum or gastric aspirates, and 5) 3 of the 6 signs and symptoms compatible with TB. Signs and symptoms of TB were cough or wheezing of $\geq 2$ weeks, unexplained fever $\geq 2$ weeks after common causes excluded, weight loss or failure to gain weight or weight faltering or anorexia, failure to respond to $\geq 2$ weeks of antimicrobial therapy when treated for a lower respiratory tract infection, failure to return to baseline health status after $\geq 2$ weeks after a viral infection or exanthema, and fatigue/ 


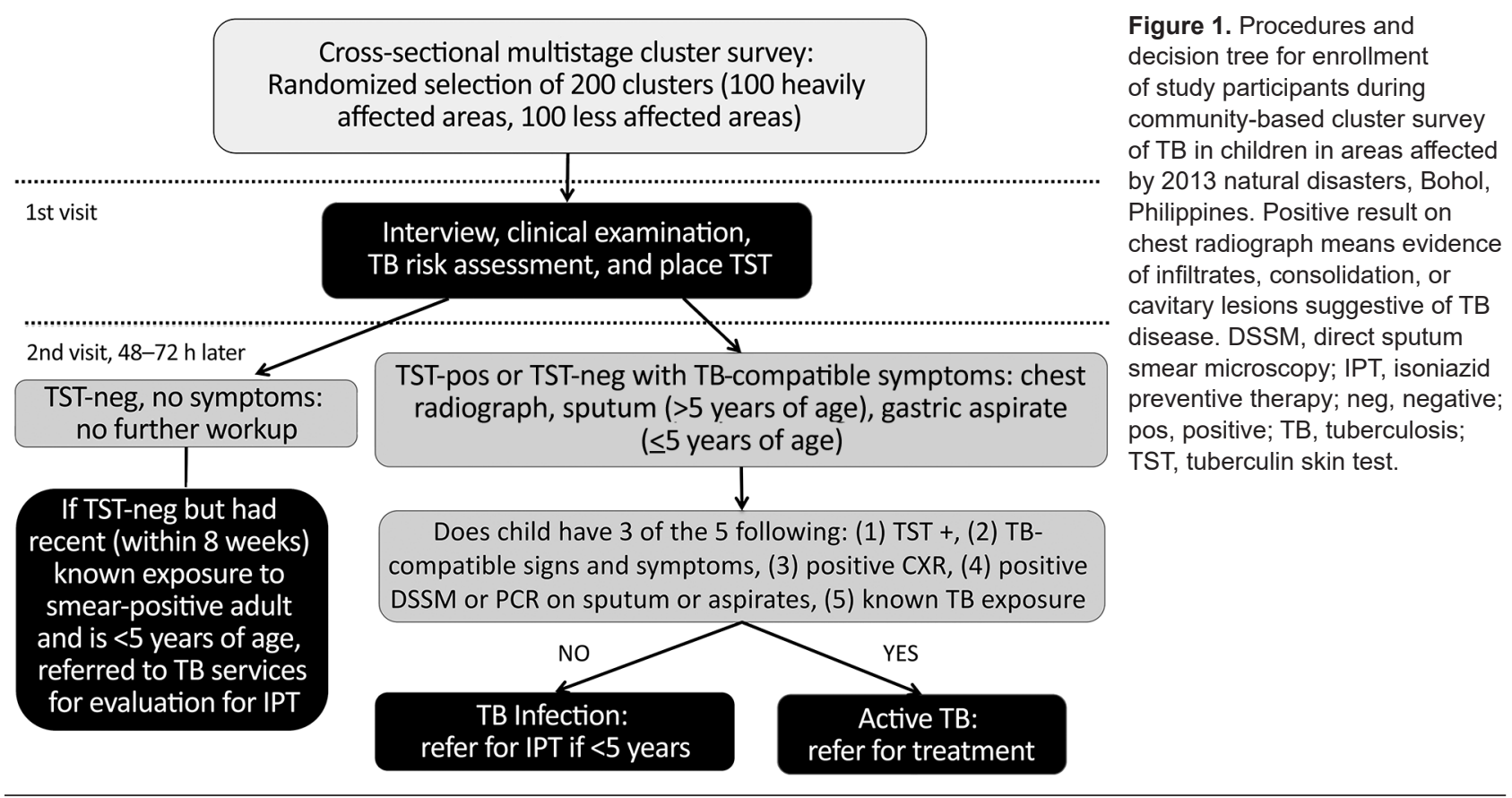

lethargy or reduced playfulness (11). Participants in whom illnesses other than TB were diagnosed also were referred to the local health center for medical management. The Institutional Review Boards of the University of the Philippines Manila (Manila, Philippines) and Baylor College of Medicine (Houston, TX, USA) reviewed and approved this study.

\section{Data Analysis}

All data were entered into EpiInfo version 7.2 (US Centers for Disease Control and Prevention, https://www.cdc. gov/epiinfo/index.html) on password-protected computers and were continuously backed up to a US-based protected server accessible only by study personnel. Statistical analyses were performed using Epilnfo and NCSS (NCSS, Inc., https://www.ncss.com). We determined the weighted prevalence of TST positivity (including diagnosed TB) and calculated Wilson 95\% CIs. We then used univariate logistic regression with calculation of odds ratios (ORs) and $95 \%$ CIs to examine whether the prevalence of TST positivity in heavily affected areas differed significantly from that in less affected areas. We also performed univariate analysis on all other collected variables that could potentially influence the risk for TST positivity. Multivariate logistic regression analysis was then performed on all variables identified on univariate analysis with a $p$ value $<0.25$ to determine independent risk factors for TST positivity in Bohol. We used a stepwise-backward approach to eliminate variables with the highest $p$ value until all remaining variables had a $p$ value $\leq 0.05$. Model building strategies included interaction terms to determine effect modification and confounding.

\section{Results}

During 2016-2018, a total of 5,476 children $(2,710$ in heavily affected areas and 2,766 in less affected areas) were enrolled from the 14 municipalities from the 184 villages selected for the 200 clusters. We enrolled an average of 3.9 children per household, exceeding our original sample size estimate of 3 children per household.

A total of 355 children were TST positive (weighted prevalence $6.4 \%$ [95\% CI $6.3 \%-6.5 \%]$ ). Three of the 14 municipalities had a TST-positive prevalence $>10 \%$ ( 1 in heavily affected areas, 2 in less affected areas; Table 1, Figure 2), and 12 villages had TST-positive prevalence $>20 \%$ (Appendix Table 3 ). Two remote villages (1 in heavily affected areas, 1 in less affected areas) had the highest prevalence ( $29 \%$ each). Of the 16 island villages located offshore from mainland Bohol, 9 (56\%) had prevalence $\geq 10 \%$, compared with $38(22 \%)$ of the 168 villages on mainland Bohol.

Sex was not associated with TST positivity (Table 2). Older age was significantly associated with TST positivity; prevalence increased markedly $(>10 \%)$ in children $\geq 10$ years of age (Figure 3). Variables identified on univariate analysis as being significant risks for TST positivity were being older ( $\geq 6$ years of age), living in 1 of the island villages away from mainland Bohol, having a history of TB treatment, having $\geq 6$ persons living in the home, having a history of contact with a person with $\mathrm{TB}$, and having $\geq 2$ weeks of cough during the preceding month.

Most (75.4\%) of the children enrolled were already born and living in Bohol during the earthquake, and almost half $(47.4 \%)$ were displaced. Among those in Bohol during the earthquake, living in a shelter with $\geq 25$ 
Tuberculosis in Children After Natural Disasters

Table 1. Prevalence of TST positivity by municipality and area affected by 2013 natural disasters, Bohol, Philippines, $2016-2018^{*}$

\begin{tabular}{|c|c|c|c|c|}
\hline Municipality† & $\begin{array}{c}\text { Total population } † \text { of } \\
\text { municipality } \ddagger\end{array}$ & $\begin{array}{c}\text { Total no. children } \\
\text { enrolled }\end{array}$ & $\begin{array}{c}\text { Total no. TST } \\
\text { positive§ }\end{array}$ & Prevalence, $\%(95 \% \mathrm{Cl})$ \\
\hline Heavily affected area & 199,653 & 2,710 & 160 & $5.9(5.0-6.8)$ \\
\hline Loon & 42,729 & 550 & 14 & $2.5(1.2-3.9)$ \\
\hline Calape & 30,146 & 260 & 11 & $4.2(1.8-6.7)$ \\
\hline Maribojoc & 20,477 & 168 & 11 & $6.5(2.8-10.3)$ \\
\hline Clarin & 20,277 & 267 & 16 & $6.0(3.1-8.9)$ \\
\hline Catigbian & 22,675 & 624 & 19 & $3.0(1.7-4.4)$ \\
\hline Inabanga & 43,272 & 537 & 62 & $11.5(8.8-14.3)$ \\
\hline Sagbayan & 20,077 & 304 & 27 & $8.9(5.7-12.1)$ \\
\hline Less affected area & 213,899 & 2,766 & 195 & $7.0(6.1-8.0)$ \\
\hline Ubay & 68,482 & 653 & 48 & $7.4(5.3-9.4)$ \\
\hline Bien Unido & 25,782 & 162 & 17 & $10.5(5.7-15.3)$ \\
\hline Pres. Carlos P. Garcia & 23,269 & 212 & 29 & $13.7(9.0-18.3)$ \\
\hline Anda & 16,866 & 327 & 21 & $6.4(3.8-9.1)$ \\
\hline Mabini & 28,172 & 722 & 51 & $7.1(5.2-8.9)$ \\
\hline Candijay & 29,043 & 457 & 27 & $5.9(3.7-8.1)$ \\
\hline Alicia & 22,285 & 233 & 2 & $0.9(-0.3-2.1)$ \\
\hline
\end{tabular}

*TST, tuberculin skin test.

tHeavily affected and less affected areas each comprised 100 clusters/700 households.

¥Population is based on the 2010 national census (7).

§TST Positives includes all tuberculosis cases, including the 1 child with tuberculosis who was TST negative because of malnutrition

persons approached significance for increased risk for TST positivity on univariate analysis (OR $1.5,95 \%$ CI 0.98 $2.2 ; \mathrm{p}=0.06)$. We noted no significant difference in TST positivity between heavily affected and less affected areas (Table 3). A higher proportion of TST-positive children were from the less affected areas, but this finding was not statistically significant.

On the basis of results from the univariate analyses, we entered the following variables into the multivariate logistic regression model to determine which factors were independent risks for TST positivity: age category (6-14 years), history of TB treatment, prior contact with a person known to have TB, recent history of cough for $\geq 2$ weeks, living on a remote island village, and living with $\geq 25$ persons during displacement after the earthquake. Based on backward, stepwise multivariate logistic regression modeling, being older (OR 1.6; 95\% CI 1.2-2.0), having a history of TB treatment (OR 3.4; 95\% CI 1.7-6.7), contact with a person known to have TB (OR 4.9; 95\% CI 3.8-6.2), and living on a remote island village (OR 1.5 ; 95\% CI 1.1-2.1) were independent risk factors for TST positivity (Table 4).

According to history provided by caregivers, $57(1 \%)$ children were previously treated for TB; only $12(22 \%)$ were TST positive (Table 2). We were unable to assess whether the treatment administered was isoniazid preventive therapy for TB exposure or latent infection or was treatment for active disease. Of the 57 reporting prior TB treatment, $47(82 \%)$ completed the course of treatment,

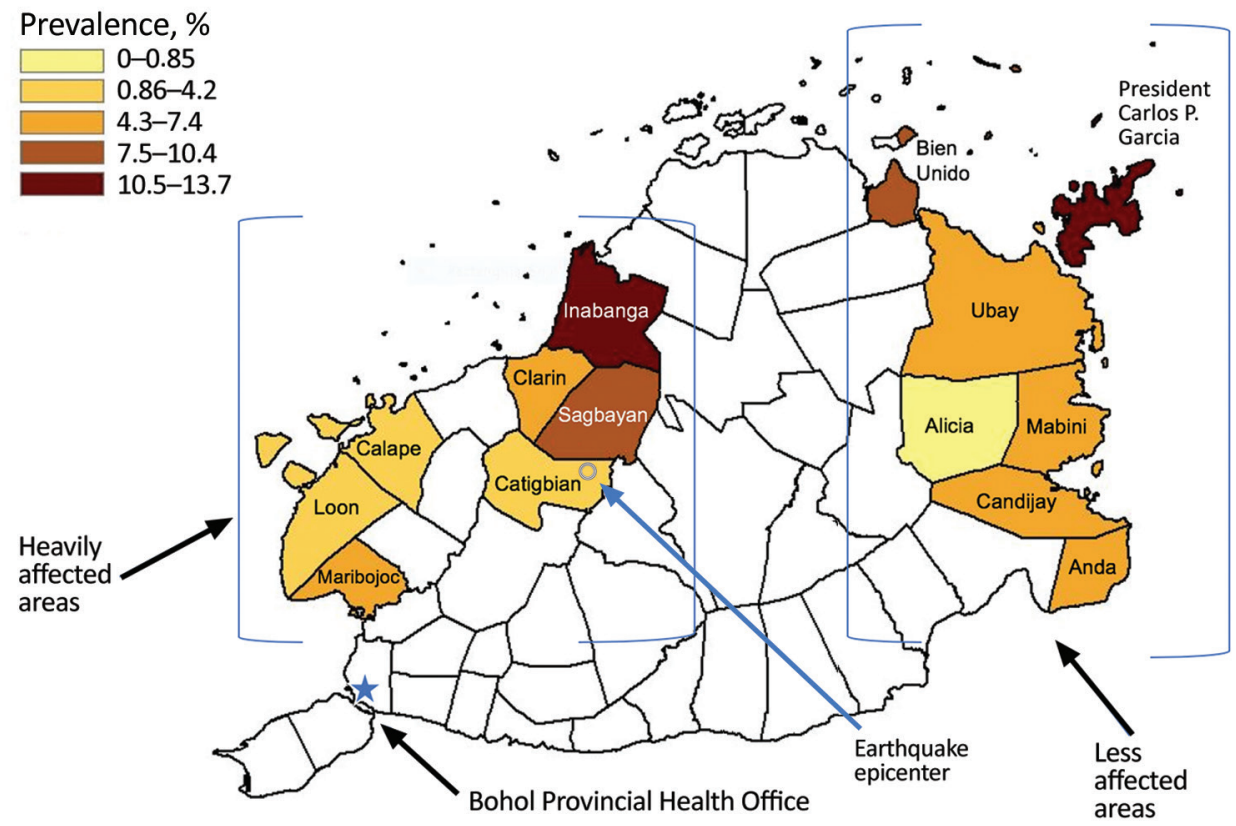

Figure 2. Prevalence of tuberculin skin test positivity by municipality obtained in study of tuberculosis in children in areas affected by 2013 natural disasters, Bohol, Philippines, 2016-2018. Epicenter of 2013 earthquake is indicated. 
Table 2. Demographic, social, and clinical histories of enrolled children in cluster survey of TB in children in areas affected by 2013 natural disasters, Bohol, Philippines*

\begin{tabular}{|c|c|c|c|c|c|}
\hline \multirow[b]{2}{*}{ Characteristic } & \multirow[b]{2}{*}{ Total, $n=5,476(\%)$} & \multicolumn{2}{|c|}{ TST } & \multirow[b]{2}{*}{ OR $(95 \% \mathrm{Cl})$} & \multirow[b]{2}{*}{$p$ value } \\
\hline & & Positive† $n=355$ & Negative, $n=5,121$ & & \\
\hline Male sex & $2,862(52.3)$ & $179(50.4)$ & $2,684(52.4)$ & $1.1(0.9-1.4)$ & 0.44 \\
\hline Median age, y (IQR) & $5.8(5.3)$ & $7.8(6.3)$ & $5.8(5.2)$ & & \\
\hline $0-5$ & $2,811(51.3)$ & $133(37.5)$ & $2,678(52.3)$ & Reference & \\
\hline $6-14$ & $2,665(48.7)$ & $222(62.5)$ & $2,443(47.7)$ & $1.8(1.5-2.3)$ & $<0.001$ \\
\hline Island village & $375(6.8)$ & $48(13.5)$ & $327(6.4)$ & $2.3(1.7-3.2)$ & $<0.001$ \\
\hline Prior treatment for TB & $57(1.0)$ & $12(3.4)$ & $45(0.9)$ & $4.0(2.1-7.6)$ & $<0.001$ \\
\hline $\begin{array}{l}\text { Median no. persons living in household } \\
\text { before earthquake (range) }\end{array}$ & $5(1-21)$ & $6(1-15)$ & $5(1-21)$ & $1.1(1.0-1.1)$ & 0.009 \\
\hline$\geq 6$ Persons living in home & $2,586(47.2)$ & $193(54.4)$ & $2,393(46.7)$ & $1.4(1.1-1.7)$ & 0.005 \\
\hline $\bar{S}$ mokers in the home & $3,049(55.7)$ & $208(58.6)$ & $2,841(55.5)$ & $1.1(0.9-1.4)$ & 0.23 \\
\hline Child had contact with person with TB & $658(12.0)$ & $136(38.3)$ & $522(10.2)$ & $5.4(4.3-6.8)$ & $<0.001$ \\
\hline Recent history of cough for $\geq 2$ wk $\ddagger$ & $104(1.9)$ & $26(7.3)$ & $78(1.5)$ & $4.9(3.1-7.7)$ & $<0.001$ \\
\hline
\end{tabular}

$8(14 \%)$ did not complete treatment, and $2(4 \%)$ had unknown treatment adherence. All 8 children who did not complete treatment were from villages that were hard to reach because of distance or accessibility. Reasons for not completing treatment were inability to purchase medications ( 5 children); erratic medicine supply ( 2 children); and distance from clinic, adverse medicine events, unpleasant taste, and difficult medication administration (1 child each). For 2 children, $>1$ barrier was listed for not completing treatment.

Intrathoracic TB was diagnosed in $16(0.3 \%)$ children (median age 6 years) (Table 5). Three (24\%) had
A

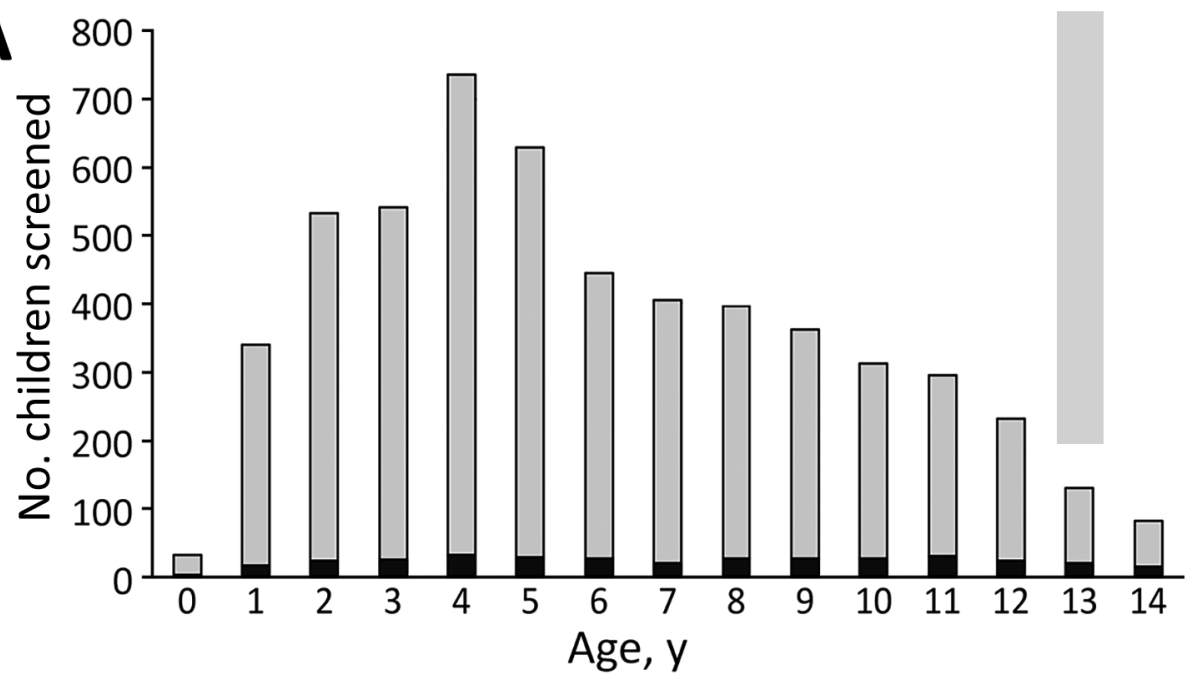

B

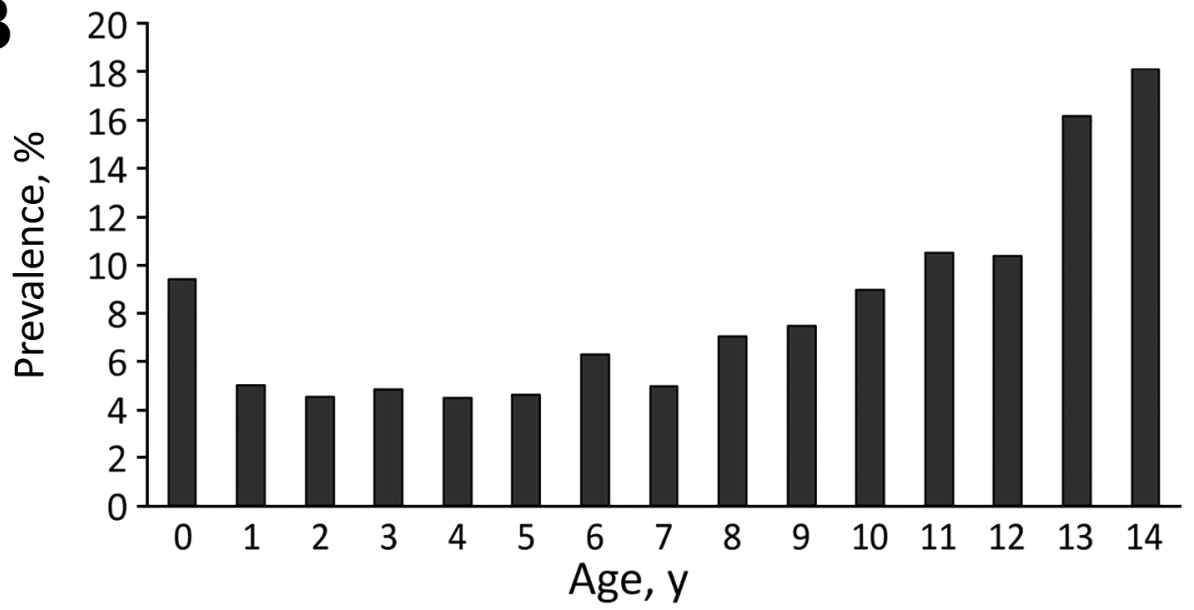

Figure 3. Distribution of patients by age in study of tuberculosis in children in areas affected by 2013 natural disasters, Bohol, Philippines.

A) Number of children who screened positive by TST; B) prevalence of TST positivity. Black bars, TST positive; gray bars, TST negative. TST, tuberculin skin test. 
Tuberculosis in Children After Natural Disasters

Table 3. Factors related to 2013 earthquake and subsequent displacement on TST positivity in children in areas affected by 2013 natural disasters, Bohol, Philippines*

\begin{tabular}{|c|c|c|c|c|c|}
\hline \multirow[b]{2}{*}{ Factor } & \multirow[b]{2}{*}{$\begin{array}{c}\text { Total no. }(\%), \mathrm{n}= \\
5,476\end{array}$} & \multicolumn{2}{|c|}{ TST } & \multirow[b]{2}{*}{$\begin{array}{l}\text { Odds ratio } \\
(95 \% \mathrm{Cl})\end{array}$} & \multirow[b]{2}{*}{$\mathrm{p}$ value } \\
\hline & & $\begin{array}{c}\text { Positive, no. (\%), } † \\
n=355\end{array}$ & $\begin{array}{c}\text { Negative, no. (\%), } \\
n=5,121\end{array}$ & & \\
\hline \multicolumn{6}{|l|}{ Earthquake-affected area } \\
\hline Heavily affected area & $2,710(49.5)$ & $160(45.1)$ & $2,550(49.8)$ & $1.2(0.97-1.5)$ & 0.09 \\
\hline Less affected area & $2,766(50.5)$ & $195(54.9)$ & $2,571(50.2)$ & & \\
\hline Child lived in Bohol during earthquake & $4,131(75.4)$ & $278(78.3)$ & $3,853(75.2)$ & $1.2(0.92-1.5)$ & 0.20 \\
\hline Child was displaced & $1,959 / 4,131(47.4)$ & $113 / 278(40.6)$ & $1,846 / 3,854(47.9)$ & $0.7(0.6-0.95)$ & 0.02 \\
\hline Child lived with $\geq 25$ persons in shelter & $1,081 / 1,959(55.2)$ & $72 / 113(63.7)$ & $1,009 / 1,846(54.7)$ & $1.5(0.98-2.2)$ & 0.06 \\
\hline Child displaced $>7 d$ & $777 / 1,956(39.7)$ & $50 / 113(44.2)$ & $727 / 1,843(39.4)^{\prime}$ & $1.2(0.8-1.8)$ & 0.31 \\
\hline
\end{tabular}

microbiological confirmation (all by GeneXpert). Seven (44\%) had abnormal radiographic findings consistent with TB. The most commonly reported history of recent (within 4 weeks) symptoms were cough $>2$ weeks (9 [56\%] children) and weight loss/anorexia (6 [38\%]). On physical examination, 7 (44\%) children had cervical lymphadenopathy. All 16 children with TB were included in the total number of TST-positive children in the analyses to examine risks for exposure.

Among the 1,400 households in which we conducted interviews, $148(11 \%)$ reported a household death within the 12 months before enrollment, including 10 deaths involving a family member with known or presumed TB. Among homes of TST-positive children, 17 deaths occurred in the previous year; 6 households reported death of a family member with known or presumed TB.

\section{Discussion}

We assessed the risk for TB in a postdisaster setting among a large population of children using a methodologically rigorous study design. The prevalence of TST positivity was higher than we expected and disparate, even in a relatively small island province in the Philippines, and TST positivity in some villages approached $30 \%$. Considering the weighted prevalence of TST positivity of $6.4 \%$ and that 422,148 children live in Bohol (7), we can estimate that $\approx 27,000$ children are TST positive in this 1 province. At the time of this study, TST prevalence for children in the Philippines was unknown. Although we did not find TST positivity to be significantly higher in disaster-affected areas in Bohol as a result of resource interruptions as we originally hypothesized, positivity was associated with geographic barriers (i.e., island villages) and approached significance with increased risk resulting from crowding in emergency shelters. In adults, smear positivity and illness and death increased after natural and humanmade disasters in countries in Central America (13), Eastern Europe (14), and Africa (15). Our data add a perspective for children and are consistent with data reported for TB for adults in developing countries after complex humanitarian emergencies.
The high prevalence of TST positivity among subgroups of children in Bohol was unexpected. Unfortunately, we know of no prior studies in children in this region that would have enabled us to document baseline or estimate the expected prevalence. Villages with high prevalence of TST positivity might plausibly have unique risk factors for TB (e.g., geographically isolated and disadvantaged areas having poor socioeconomic status or limited access to care). TSTs also might have overestimated the incidence of $M$. tuberculosis infection resulting from cross-reactions with BCG (10). In the Philippines, BCG is administered only once, soon after birth (17), which provides a lower risk for false positive TSTs than in countries where BCG is boosted or administered to older children (18). Also, if cross-reactions were common, we would not have observed such variation in prevalence of TST positivity across Bohol, particularly in older children, which was the higher risk group.

Robust national and international data demonstrate that TB occurs in pockets of persons and varies substantially across geographic regions $(19,20)$. Although some clustering of cases may be explained by underlying medical, social, or economic conditions (e.g., diabetes, socioeconomic status, and care access issues), explanations for clustering are not always evident. We found higher TST positivity in island villages where geographic barriers prevented immediate access to the municipal health units on mainland Bohol. Increasing distance from public healthcare facilities can result in diagnostic delays and missed diagnoses, particularly for TB, where control programs often use centralized models. Late disease detection in infectious

\begin{tabular}{|c|c|c|}
\hline Variable & OR $(95 \% \mathrm{Cl})$ & $\mathrm{p}$ value \\
\hline $\begin{array}{l}\text { History of contact with a person } \\
\text { known to have TB }\end{array}$ & $4.9(3.8-6.2)$ & $<0.001$ \\
\hline History of treatment for TB & $3.4(1.7-6.9)$ & $<0.001$ \\
\hline Older age, 6-14 y & $1.6(1.2-2.0)$ & $<0.001$ \\
\hline Living on a remote island village & $1.5(1.1-2.1)$ & 0.02 \\
\hline
\end{tabular}

${ }^{*}$ OR, odds ratio; TB, tuberculosis; TST, tuberculin skin test. 
Table 5. Clinical and diagnostic findings for 16 persons with TB in cluster survey of TB in children in areas affected by 2013 natural disasters, Bohol, Philippines, 2016-2018*

\begin{tabular}{|c|c|c|c|c|c|c|c|}
\hline $\begin{array}{l}\text { Case } \\
\text { no. }\end{array}$ & $\begin{array}{l}\text { Natural } \\
\text { disaster } \\
\text { area }\end{array}$ & $\begin{array}{l}\text { Age, } \\
\text { y/sex }\end{array}$ & $\begin{array}{l}\text { Known } \\
\text { exposure } \\
\text { to TB }\end{array}$ & History of signs/symptoms & $\begin{array}{c}\text { Chest radiograph interpretation } \\
\text { by radiologist }\end{array}$ & $\begin{array}{l}\text { DSSM } \\
\text { result } †\end{array}$ & $\begin{array}{l}\text { GeneXpert } \\
\text { result† }\end{array}$ \\
\hline 1 & LAA & $6 / \mathrm{M}$ & Yes & $\begin{array}{l}\text { Cough }>2 \text { weeks, wheezing, } \\
\text { weight loss; no improvement } \\
\text { after taking antimicrobial drugs }\end{array}$ & $\begin{array}{l}\text { Pneumonia, both paracardiac } \\
\text { areas }\end{array}$ & Neg & Neg \\
\hline 2 & LAA & 2/M & Yes & $\begin{array}{l}\text { Cough }>2 \text { weeks, weight loss, } \\
\text { malaise; no improvement after } \\
\text { taking antimicrobial drugs }\end{array}$ & $\begin{array}{l}\text { Inflammatory process, both } \\
\text { inner zones }\end{array}$ & Neg & $\begin{array}{l}\text { Invalid, after } \\
2 \text { extractions }\end{array}$ \\
\hline 3 & LAA & $8 / \mathrm{M}$ & Yes & Cervical lymphadenopathy & $\begin{array}{l}\text { Calcified hilar lymphadenopathy, } \\
\text { likely representing a chronic } \\
\text { process, such as pulmonary TB }\end{array}$ & $\mathrm{Neg}$ & Neg \\
\hline 4 & LAA & $14 / \mathrm{M}$ & Yes & $\begin{array}{l}\text { None; history of prior TB } \\
\text { treatment but did not complete } \\
\text { therapy }\end{array}$ & $\begin{array}{l}\text { Inflammatory process in left } \\
\text { apical area compatible with } \\
\text { chronic process, such as } \\
\text { pulmonary TB with minimal } \\
\text { apical pleural thickening }\end{array}$ & Neg & Neg \\
\hline 5 & LAA & 7/F & Yes & Cough $>2$ weeks & Normal & Neg & Neg \\
\hline 6 & LAA & $4 / \mathrm{M}$ & Yes & $\begin{array}{l}\text { Cough }>2 \text { weeks, weight loss, } \\
\text { anorexia, malaise, chest pain }\end{array}$ & Normal & Neg & Neg \\
\hline 7 & LAA & $5 / \mathrm{M}$ & Yes & Cervical lymphadenopathy & $\begin{array}{l}\text { Inflammatory process in the left } \\
\text { retrocardiac area }\end{array}$ & Neg & Neg \\
\hline 8 & HAA & $14 / \mathrm{F}$ & Yes & None & Normal & $\mathrm{Neg}$ & Pos \\
\hline 9 & LAA & $5 / F$ & Yes & $\begin{array}{c}\text { Cough }>2 \text { weeks, fever, weight } \\
\text { loss }\end{array}$ & Normal & Neg & Pos \\
\hline 10 & LAA & $1 / F$ & Yes & $\begin{array}{l}\text { Cough }>2 \text { weeks, fever, } \\
\text { dyspnea, no improvement after } \\
\text { taking antimicrobial drugs }\end{array}$ & Normal & Neg & Neg \\
\hline 11 & LAA & $12 / \mathrm{F}$ & No & $\begin{array}{l}\text { Coughing >2 weeks, fever, } \\
\text { chest and back pain, weight } \\
\text { loss, cervical lymphadenopathy }\end{array}$ & Normal & Neg & $\mathrm{Neg}$ \\
\hline 12 & LAA & $11 / \mathrm{F}$ & Yes & $\begin{array}{l}\text { Cervical lymphadenopathy, no } \\
\text { rales or wheezing }\end{array}$ & Normal & Neg & Neg \\
\hline 13 & LAA & $3 / \mathrm{M}$ & Yes & Cervical lymphadenopathy & Normal & $\mathrm{Neg}$ & $\mathrm{Neg}$ \\
\hline 14 & LAA & $6 / \mathrm{M}$ & Yes & Cervical lymphadenopathy & Normal & $\mathrm{Neg}$ & $\mathrm{Neg}$ \\
\hline 15 & LAA & $3 / \mathrm{F}$ & Yes & Coughing $>2$ weeks, weight loss & Bilateral pneumonia & Neg & Neg \\
\hline 16 & HAA & 10/M & Yes & $\begin{array}{l}\text { Coughing }>2 \text { weeks, weight } \\
\text { loss, cervical lymphadenopathy }\end{array}$ & $\begin{array}{l}\text { Pneumonia, both lower lungs, } \\
\text { minimal left pleural effusion vs. } \\
\text { pleural thickening; consider } \\
\text { Potts disease (extrapulmonary } \\
\text { TB) involving T12 and L1 } \\
\text { vertebrae with Gibbus deformity }\end{array}$ & Neg & Pos \\
\hline
\end{tabular}

*DSSM, direct sputum smear microscopy; HAA, heavily affected area; LAA, less affected area; neg, negative; pos, positive; TB, tuberculosis.

†Direct smears and GeneXpert (Cepheid, http://www.cepheid.com) performed on sputum for children $>5$ years of age and gastric aspirates for children $\leq 5$ years of age.

adults has substantial implications for children, including increasing M. tuberculosis infection and missed opportunities for preventive health services, outreach, and public health intervention.

In our study, other factors independently associated with TST positivity included older age, history of contact with a person known to have TB, and history of TB treatment. These statistical findings were expected because older children have a longer possible period of exposure risk over the course of their childhood. Similarly, known contact with a person with TB and history of TB treatment would greatly influence TST positivity. Although our finding of higher TST-positive prevalence in less affected areas than in heavily affected areas was not significant, we did not expect to find it. We hypothesize this finding was because less affected areas were much farther from the
Provincial Health Office, where TB resources are distributed to the entire province. This discrepancy is worth investigating further to understand whether availability and access to resources affects TB transmission in this region.

Historically, TB prevention and treatment efforts have focused on adults for epidemiologic, economic, and practical reasons. M. tuberculosis-infected children are reservoirs for future cases and transmitters of disease. Given their youth, children are less likely to experience adverse side effects of TB prevention treatment and experience greater long-term benefits than adults, presuming they are not reinfected by the original source. Additionally, in many developing nations, children account for nearly $50 \%$ of the population. Thus, changing the emphasis of treatment and prevention programs to be more inclusive of children is needed but requires modification in provider 
education, expansion of diagnostic tools, caregiver support, and more readily available access to child-friendly medication formulations.

During natural disasters, disruption of TB control poses a threat to both industrialized and resource-limited nations, as seen after the 2011 earthquake in Japan, the 2010 earthquake in Haiti, and the 2005 Hurricane Katrina in the United States $(15,21,22)$. Experience has demonstrated that major impediments to successful reconstruction of TB services include mobile populations, destroyed infrastructure, and lack of coordination, leading to poor case detection and suboptimal TB control (15). Our findings suggest that displacement after natural disasters may increase the future risk for TB in affected communities. Because public health resources are often introduced into communities after disasters, we propose that the postdisaster recovery period might provide a unique window of opportunity to introduce interventions to sustainably improve TB control.

Our study had some limitations. Epidemiologic risk factors were family-reported and subject to recall bias, particularly because this study was conducted $3-5$ years after the natural disasters. Crowding in shelters with nonrelatives might have resulted in underestimating TB contacts for children. Interferon $\gamma$-release assays were unavailable; some TST positivity might have resulted from cross-reaction from BCG. However, older children were significantly more likely than younger children to be TST positive, which would not be expected if TST positivity were due solely to BCG. Although we presume that BCG uptake is high according to national data, we did not collect vaccine status individually at enrollment. The unavailability of mycobacterial cultures potentially caused an underestimation of the TB prevalence. Unfortunately, the number of active TB cases was small, so we were concerned about performing and interpreting any statistical analyses for risk; however, when active cases were examined independently in our model, the risks remained the same for this group with the exception of older age. Our findings might not be generalizable to other disaster settings in less populated regions or in areas with lower baseline TB incidence.

In conclusion, in a large, community-based screening for $M$. tuberculosis infection in children $<15$ years of age in the Philippines, we found a high prevalence of TST positivity, especially in geographically isolated villages. We demonstrated the feasibility and highlight the importance of implementing active TB case-finding in a resource-poor setting despite population displacement and postdisaster service-line interruption. One step to bolster postdisaster mitigation is a strong baseline national TB program that includes local stakeholders (including not only healthcare workers but also community and government leaders), reaches marginalized populations, and considers the differential vulnerability of children before a disaster.
Additional members of the PEER Health Bohol Pediatric Study Team who contributed data to this study: Hazel M.

Remolador, Zarah Jane H. Tubiano, Rhea Annvi H. Lofranco, Ellen D. Lague, Riovi May S. Salmasan, Katherine Ngo, Caya R. Estoque, Fernando B. Lopos, Diozele Hazel M. Sanvictores, Carmelita D. Amora, Maureen Mae C. Riña, Catherine O. Calipes, Jeia Pondoc, Marlo Tampon, Myra Riccil Estose, Reymoses Cabagnot, Polizena Rances, Mutya Kismet T. Macuno, Crisanta Estomago, and Nelson Elle.

\section{Acknowledgments}

We thank the families and children who participated in this study. We also thank the physicians, nurses, and health workers at the Provincial Health Office, Municipal Rural Health Units, and Barangay Health Stations.

This study was funded by the US Agency for International Development and the US National Academy of Sciences through the PEER Health Program.

\section{About the Author}

Dr. Murray is a professor in pediatrics and molecular virology and microbiology and is the vice chair for research in the Department of Pediatrics, director of the William T. Shearer Center for Human Immunobiology, and assistant dean of the National School of Tropical Medicine, Baylor College of Medicine and Texas Children's Hospital, Houston, Texas, USA. Her research interests include the epidemiology and clinical investigation of infectious diseases.

\section{References}

1. Philippine Humanitarian Country Team UNOftCoHA. Philippines: Bohol earthquake action plan (revised). January 2014 [cited 2018 Nov 30]. https://reliefweb.int/sites/reliefweb.int/files/resources/ Bohol $\% 20$ Earthquake $\% 20$ Action $\% 20$ Plan $\% 20 \% 28$ BEAP $\% 29 \% 20$ Revision\%20FINAL.pdf

2. Survey MotPNTP. 2016 National Tuberculosis Prevalence Survey for the Department of Health, Philippines [cited 2019 Jan 22]. http://ntp.doh.gov.ph/downloads/publications/ NTPS2016.pdf

3. Kanamori H, Hatakeyama T, Uchiyama B, Weber DJ, Takeuchi M, Endo S, et al. Clinical and molecular epidemiological features of tuberculosis after the 2011 Japan earthquake and tsunami. Int J Tuberc Lung Dis. 2016;20:505-14. http://dx.doi.org/ 10.5588/ijtld. 15.0607

4. Moss WJ, Ramakrishnan M, Storms D, Henderson Siegle A, Weiss WM, Lejnev I, et al. Child health in complex emergencies. Bull World Health Organ. 2006;84:58-64. http://dx.doi.org/ 10.2471/BLT.04.019570

5. Bohol-Philippines.com Best Ecotourism Destinations. Bohol Islands [cited 2019 Apr 26]. https://www.bohol-philippines.com/ bohol-island.html

6. Republic of the Philippines Department of Health. What is GIDA? [cited 2019 Jan 22]. https://www.doh.gov.ph/node/1154

7. Republic of the Philippines National Statistics Office. 2010 Census of population and housing. Report no. 2A. Demographic 
and housing characteristics (non-sample variables). Bohol [cited 2018 Nov 30]. https://psa.gov.ph/sites/default/files/ BOHOL_FINAL\%20PDF.pdf

8. World Health Organisation. Philippines: WHO and UNICEF estimates of immunization coverage: 2017 revision [cited 2019 Apr 24]. https://www.who.int/immunization/monitoring_surveillance/ data/phl.pdf

9. Bennett S, Woods T, Liyanage WM, Smith DL. A simplified general method for cluster-sample surveys of health in developing countries. World Health Stat Q. 1991;44:98-106.

10. Vianzon R, Garfin AM, Lagos A, Belen R. The tuberculosis profile of the Philippines, 2003-2011: advancing DOTS and beyond. Western Pac Surveill Response J. 2013;4:11-6. http://dx.doi.org/10.5365/wpsar.2012.3.4.022

11. PhilHealth. National Tuberculosis Control Program, manual of procedures. 5th ed. [cited 2018 Dec 3]. https://www.philhealth. gov.ph/partners/providers/pdf/NTCP_MoP2014.pdf

12. Graham SM, Cuevas LE, Jean-Philippe P, Browning R, Casenghi M, Detjen AK, et al. Clinical case definitions for classification of intrathoracic tuberculosis in children: an update. Clin Infect Dis. 2015;61(Suppl 3):S179-87. http://dx.doi.org/10.1093/cid/civ581

13. Barr RG, Menzies R. The effect of war on tuberculosis. Results of a tuberculin survey among displaced persons in El Salvador and a review of the literature. Tuber Lung Dis. 1994;75:251-9. http://dx.doi.org/10.1016/0962-8479(94)90129-5

14. Toole MJ, Waldman RJ. Refugees and displaced persons. War, hunger, and public health. JAMA. 1993;270:600-5. http://dx.doi.org/10.1001/jama.1993.03510050066029

15. Coninx R. Tuberculosis in complex emergencies. Bull World Health Organ. 2007;85:637-40. http://dx.doi.org/10.2471/ BLT.06.037630

16. Howley MM, Painter JA, Katz DJ, Graviss EA, Reves R, Beavers SF, et al.; Tuberculosis Epidemiologic Studies Consortium. Evaluation of QuantiFERON-TB gold in-tube and tuberculin skin tests among immigrant children being screened for latent tuberculosis infection. Pediatr Infect Dis J. 2015;34:35-9. http://dx.doi.org/10.1097/INF.0000000000000494

17. Aguirre CA. Philippines childhood immunization schedule, 2016 [cited 2018 Dec 3]. http://www.pidsphil.org/pdf/2016/ 16LEC-10-PIDSP-Immunization-Schedule-2016-Aguirre.pdf

18. Zwerling A, Behr MA, Verma A, Brewer TF, Menzies D, Pai M. The BCG World Atlas: a database of global BCG vaccination policies and practices. PLoS Med. 2011;8:e1001012. http://dx.doi.org/10.1371/journal.pmed.1001012

19. Jenkins HE, Gegia M, Furin J, Kalandadze I, Nanava U, Chakhaia T, et al. Geographical heterogeneity of multidrugresistant tuberculosis in Georgia, January 2009 to June 2011. Euro Surveill. 2014;19:20743. http://dx.doi.org/10.2807/1560-7917. ES2014.19.11.20743

20. Winston CA, Menzies HJ. Pediatric and adolescent tuberculosis in the United States, 2008-2010. Pediatrics. 2012;130:e1425-32. http://dx.doi.org/10.1542/peds.2012-1057

21. Furin J, Mathew T. Tuberculosis control in acute disaster settings: case studies from the 2010 Haiti earthquake. Disaster Med Public Health Prep. 2013;7:129-30. http://dx.doi.org/10.1017/ dmp.2013.7

22. Bieberly J, Ali J. Treatment adherence of the latently infected tuberculosis population (post-Katrina) at Wetmore TB Clinic, New Orleans, USA. Int J Tuberc Lung Dis. 2008;12:1134-8.

Address for correspondence: Salvacion R. Gatchalian, Section of Infectious and Tropical Diseases in Pediatrics, Department of Pediatrics, UP-PGH, Taft Avenue, Manila 1000, Philippines; email:

sallymd77@yahoo.com

\section{EID podcast Bird Migration and West Nile Virus in the U.S.}

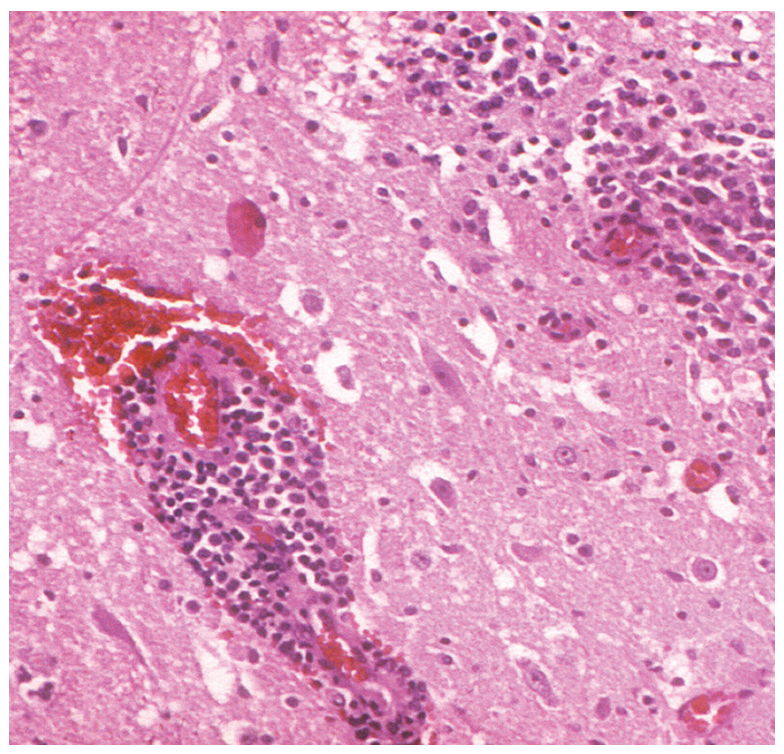

West Nile virus cycles between birds and mosquitoes that then infect humans through bites. But birds don't tend to stay in one place, and neither does the virus; a recent study has mapped how the disease has evolved along known migration routes.

In this EID podcast, Dr. Alan Barrett, Professor and Vice Chair for Research in the Department of Pathology at the University of Texas, Medical Branch, explores how bird migration patterns influence the epidemiology of West Nile virus in the U.S.

\section{Visit our website to listen: https: / /go.usa.gov/xy6n EMERGING INFECTIOUS DISEASES}

